\title{
Akira Saito y Claudia Rosas (eds.), Reducciones. La Concentración forzada de las poblaciones indígenas en el Virreinato del Perú, Lima, Fondo Editorial Pontificia Universidad Católica del Perú/ Osaka, National Museum of Ethnology, 2017, 678 pp.
}

Reducciones es el fruto de una serie de investigaciones entre los años 2010 y 2014, y resultado de un acuerdo de cooperación entre el National Museum of Ethnology de Japón y el Programa de Estudios Andinos de la Pontificia Universidad Católica del Perú. Corresponde a la contribución de quince autores, organizados bajo un criterio temático-geográfico; Alto Perú, Lima y sus valles, Costa norte del Perú, Sierra central, Sierra sur, la Amazonía, Paraguay y Chile, siendo los primeros dos capítulos dedicados a la explicación de las políticas reduccionarias toledanas entre 1569 y 1575, por parte de Jeremy Ravi Munford y Luis Miguel Glave.

A pesar de la trascendencia política que la reducción tuvo en la América española, no ha recibido la atención historiográfica que merece. Desde la década de 1970 especialistas han dedicado estudios y textos a la investigación reduccionaria, pero los editores de Reducciones admiten que corresponden solo a investigaciones de carácter descriptivo, centrando sus intereses en medidas gubernamentales en torno a estas reducciones, o en el parecer de autoridades de Madrid o Roma con respecto a la reducción misma. Los análisis de aquel entonces solo buscaban determinar si la implementación de este sistema había sido un éxito o un fracaso.

En la década de 1990 Luis Miguel Glave, quien escribe el capítulo II llamado "La cuadratura del círculo y las rendijas del encierro: Política de reducción de indios en los Andes en tiempos del virrey Toledo", calificó el estudio reduccionario como "un tema virtualmente inexplorado" y Thierry Saignes, como "una de las incógnitas más fascinantes de la historia andina". De todos modos, hay que mencionar que ciertos autores suelen dedicar unos párrafos al tema, pero no lo exploran seriamente; lo mismo ocurre con las reducciones jesuíticas, donde este proceso recibe un tratamiento descriptivo y poco analítico. Estos procesos solo son mencionados cuando se relata su fundación o se explica sus características urbanísticas, pero se dejan de lado problemáticas como la elección del sitio en donde se emplazaría la reducción, cómo se repartirían los terrenos, 
cómo sería la organización de las "parcialidades", qué relación se establecía entre el reducido y el no reducido, etcétera.

El hilo conductor de la obra nos muestra cómo se organizó la empresa reduccional por parte del virrey Francisco de Toledo y por Misiones de la Compañía de Jesús a partir de 1571. Cabe señalar que ambos proyectos incidieron directamente en la estructuración de nuevas entidades étnicas durante la colonia, así como en las delimitaciones urbanas del espacio latinoamericano caracterizado por ser un sitio planificado y uniforme, destacado por una plaza central cuadrada, una iglesia y un ayuntamiento, con calles rectas y perpendiculares cruzadas y manzanas divididas en partes iguales. El mismo fenómeno urbanístico se puede encontrar en las comunidades indígenas rurales circundantes a los grandes centros urbanos.

Desde el principio de la colonización americana por parte de España, las autoridades ibéricas consideraron que la dispersión poblacional era no solo un obstáculo para la buena administración sino que, además, un peligro para la integridad moral y espiritual de los habitantes de estas comunidades indígenas. Fue así que, para solucionar esta problemática, agentes civiles y eclesiásticos trataron de concentrar o "reducir" a las aldeas indígenas dispersas en pueblos de dimensiones mayores y con una traza urbana característica; la de damero y, de este modo, incorporar a estas comunidades a la vida en policía. Los autores destacan que la reducción fue un espacio en donde se realizó la conversión civil de los indígenas, considerado como un requisito para su transformación espiritual.

Como anteriormente se mencionó, existieron dos proyectos reduccionarios; el del quinto virrey del Perú Francisco de Toledo (1571) y el de las misiones de la Compañía de Jesús (1568), siendo el proyecto de Toledo el más conocido, destacando su carácter centralizado y autoritario, cuyo propósito era netamente la recaudación de tributos y el reclutamiento de mano de obra, aunque de todas formas la evangelización de los indígenas siempre fue la prioridad.

Entre 1570 y 1575, Toledo realizó una "visita general" en las jurisdicciones de las Audiencias de Lima y Charcas. Efectuó censos de población nativa, tasó tributos e implementó reducciones a través de visitadores. De este proyecto resultaron más de mil nuevos pueblos concentrando una población de 1.5 millones de personas. En los Andes, así como en la frontera, este proceso trajo consigo significativos cambios en la relación entre españoles e indígenas. Por ejemplo, en el Perú y en el Paraguay, esta buscaba terminar con el modus vivendi que los conquistadores y los jefes locales habían establecido a base de la encomienda. En el caso de la Amazonía como en el Chaco supuso un estado de guerra que fluctuaba con épocas de comercio.

Los liderazgos reduccionales, desde un principio, recayeron en manos de los "caciques", actuando como mediadores entre españoles e indígenas. A algunos caciques, Toledo los nombró funcionarios del Estado, pero los despojó de muchos privilegios. En las zonas fronterizas los jesuitas los nombraron "señores naturales", otorgándoles el título de DON. En el caso de Moxos, como lo describe Akira Saito en el capítulo "Consolidación y reproducción de las parcialidades tras la implementación de las reducciones en el Moxos jesuítico", los líderes tribales fueron convertidos en "capitanes de parcialidades" cuya responsabilidad era la movilización de trabajadores y soldados. Las reducciones finalmente crearon la territorialización del poder de los jefes locales. Esto, además, provocó un cambio significativo en la percepción indígena del poder político con la creación del gobierno municipal. 
El régimen reduccional tenía como objetivo la protección y promoción de los "miserables". A modo de ejemplo, se puede destacar la introducción del gobierno municipal, que según Juan de Matienzo, serviría "para que los indígenas entiendan la libertad que tienen, y comience a entrar en ellos la policía". Pero se debe mencionar que esta promesa de libertad para los naturales, rara vez fue cumplida debido a la intromisión de los corregidores, párrocos y los propios caciques, pero que sí inspiró a los plebeyos indígenas a tomar la iniciativa de fundación de sus propios pueblos como nexos a las reducciones matrices.

Cabe mencionar que entre tales empresas - llámese la toledana y la referida a las misiones jesuíticas- existen rasgos dispares. En primer término, diferencias jurisdiccionales; las reducciones toledanas se organizaban en doctrinas y sujetas a la jurisdicción de un obispo, mientras que los jesuitas estaban a cargo de una doctrina provincial y de su propia orden religiosa. Pero la diferencia más importante -desde el punto de vista de los autores- radica en la relación con el colonialismo español. Toledo subyugó a la población nativa a un régimen colonial estatal español, imponiendo tributos y trabajo forzado, además de no ofrecer protección efectiva contra funcionarios corruptos, párrocos avaros y empresarios agresivos. Por otra parte, las misiones jesuitas sirvieron como amortiguador contra los impuestos del Estado y los excesos cometidos por los colonos. A pesar de este "espacio de libertad" jesuítico, los indígenas de estas misiones no gozaban del mismo grado de libertad de los españoles. En calidad de "neófitos" eran sometidos a una administración paternalista por parte de los misioneros y a un régimen económico comunitario. Este descontento de la población nativa provocó fugas y rebeldías.

Como anteriormente se dijo, la principal misión de la concentración de indios en pueblos era la extirpación de la religión nativa y la evangelización de los indígenas. En palabras de Toledo, esta concentración sacaría a los "idólatras" de sus escondites para ser expuestos a la luz del evangelio. Se debe mencionar que el proceso en comento ayudó a la implantación del régimen mortuorio español, que posteriormente transformó el culto a los antepasados indígenas. En los Andes como en la frontera, la reducción sirvió como escenario para la catequización y la liturgia, que pretendían inculcar la fe católica en mente y cuerpo a los "neófitos". Akira Saito, además, describe en los casos de formación de cofradías, dentro de las parcialidades, que estas sirvieron como una fuerza de cohesión, así como un mecanismo de sucesión de sus nexos.

Con respecto a la población y migraciones dentro del proceso reduccionario existe gran cantidad de estudios demográficos sobre la población nativa en la América española, debido a los censos y cuentas de indios realizados por el propio Toledo y sus visitadores. Es indiscutible que el proceso aludido aceleró el descenso de la población y facilitó la propagación de enfermedades. Luego de su fundación, muchos nuevos pueblos sufrieron de la huida de su población, ya que muchos nativos retornaron a sus tierras de origen, o se trasladaban a otras reducciones, o simplemente migraban hacia las ciudades más grandes o minas. Por motivo de estas migraciones, la composición de la población que habitaba en aquellas cambió de forma significativa. Existió un cambio denominado "forestarismo", síntoma del fracaso de estas.

La reducción no era solo una unidad territorial, al contrario, representaban verdaderas repúblicas con sus propios gobiernos y recaudación de tributos. En la zona de los Andes las reducciones toledanas descompusieron a los reinos y señoríos, en el caso de las zonas fronterizas las misiones jesuíticas reunieron a variados grupos étnicos o de parentesco. En ambos casos, Andes 
y las fronteras, este proceso incubó una nueva identidad comunitaria. En el caso andino, el culto a los fundadores míticos fue eliminado y el recuerdo de los antiguos reinos y señoríos fue extirpado; en las misiones fronterizas los reducidos finalmente se identificaron con la misión, llagando a superar el apego con su parcialidad.

A pesar de la buena estructuración que Toledo imaginó con respecto a la reducción, nunca dedujo que sus principales opositores serían los propios españoles. La indignación de la élite rural española debido a la "expropiación" de sus tierras, por encontrarse en sectores fértiles y ricos para construir las reducciones, fue la primera piedra de tope. Otra fuerte oposición fue la de los propios indígenas que se negaban a abandonar sus casas, viendo quebrantado el orden de sus vidas cotidianas. Aún existiendo las oposiciones descritas, religiosos y personeros simpatizantes de los derechos de los indígenas manifestaban que esta concentración demográfica pondría a salvo a los naturales de autoridades abusivas, ya sean españolas o indígenas, y los haría más civilizados y más cristianos. Además de manifestar que cualquier cosa que sometiera a un control más estricto a la población natural sería apoyada.

Dentro del texto se pueden observar algunos términos modernos que se pueden utilizar para captar las ideas centrales que guiaron la reducción. Me refiero a los vocablos orden, policía y gobernabilidad. El orden corresponde a un principio de jerarquización que estructura a todo el universo, donde los inferiores son subordinados a los superiores. Este principio universal también se aplica al ser humano y a su sociedad, donde "cuanto esta subordinación mejor es guardada, el gobierno es mejor" (Carta de Ignacio de Loyola a los padres y hermanos de Portugal, Roma, 26 de marzo de 1553).

Las implicancias de la noción de policía, en este sentido, designan el estilo de vida conforme a las normas de urbanidad. Al intentar dar policía a los naturales, los conquistadores españoles pretendíantransmitirenellosnormas deconducta refinadas y apropiadas para los ciudadanos de estas nuevas repúblicas, refiriéndose no solo a las monarquías, sino también a los municipios (ciudades, villas y aldeas). Es así como se podrá decir que las reducciones reflejaron de manera inequívoca la concepción doble de Estado español, verticalmente ordenado, pero horizontalmente unido.

Con todo, Reducciones, La concentración forzada de las poblaciones indígenas en el Virreinato del Perú, es un obra completa y fundamental para comprender y tener una visión renovada y además actualizada del proceso en comento en la América Andina y, principalmente, en el Virreinato del Perú. Una obra que a pesar de las dificultades encontradas a causa del poco estudio y documentación existente sobre estos procesos de concentración masiva de personas, lo explica de manera magistral y demuestra que este proceso, el toledano y el jesuita, son una nueva beta historiográfica para ponderar la complejidad de un hecho histórico que recién comienza a ser develado en todos sus alcances. 